\title{
Jogos Educacionais como Ferramenta de Auxílio em Sala de Aula
}

\author{
Sebastião Rogério da Silva Neto ${ }^{1}$, Higor Ricardo M. Santos ${ }^{2}$, Anderson Alves de \\ Souza $^{1}$, Wilk Oliveira dos Santos ${ }^{1}$ \\ ${ }^{1}$ Universidade de Pernambuco, Campus Garanhuns (UPE) \\ CEP 55.294-902 - Garanhuns - PE - Brasil \\ ${ }^{2}$ Centro de Informática - Universidade Federal de Pernambuco (UFPE) \\ CEP 50.740-560 - Recife - PE - Brasil \\ \{sebast.rogers@gmail.com,higormonteiro1206@gmail.com, anderson_alves201 \\ 1 @hotmail.com, wilk.upe@gmail.com\}
}

\begin{abstract}
This paper presents an experience report about the course Educational Electronic Games offered to high school students of the School for Excellence in Middle Teaching Deolinda Amaral situated in the City of Lajedo$P E$. The following objectives of this research, we tried to promote the use of digital games for a better utilization of the content covered in class, introduce basic knowledge of programming logic and foster teamwork. Games were used in the course in order to assist students who are preparing to enter a university. It also held a competition among the students to develop the best game. And at the end of the project, it was found that there was an increased frequency in use of the laboratory for educational purposes. It is suggested that other initiatives are made based on practices presented in this work.
\end{abstract}

Resumo. Este artigo apresenta um relato de experiência sobre o curso de Jogos Eletrônicos Educacionais oferecido aos alunos do ensino médio da Escola de Referência em Ensino Médio Deolinda Amaral localizada na Cidade de Lajedo-PE. Como objetivos do trabalho, procurou-se promover a utilização de jogos digitais para um melhor aproveitamento dos conteúdos abordados em sala de aula, introduzir conhecimentos básicos de lógica de programação e fomentar o trabalho em equipe. No curso foram utilizados jogos com o propósito de auxiliar os alunos que estão se preparando para ingressar em uma universidade. Foi também realizada uma competição entre os próprios alunos para desenvolverem o melhor jogo. E ao fim do projeto, constatou-se que houve um aumento da frequência referente à utilização do laboratório para fins educacionais. Sugere-se que outras iniciativas sejam realizadas com base nas práticas apresentadas neste trabalho.

\section{Introdução}

A Tecnologia da Informação e Comunicação (TIC) tem sido uma das grandes responsáveis pelas constantes mudanças sociais e organizacionais. De acordo com a Revista INFO (2012), o mercado de TIC movimentou cerca de R \$ 102,6 bilhões em 2011 apenas no Brasil. Apesar desse investimento ser cada vez mais crescente, faltam profissionais para atender a essa demanda. Fatores como, a alta velocidade de crescimento 
e o número insuficiente de profissionais formados em Universidades e Polos tecnológicos, corroboram para que aumente a lacuna entre oferta e demanda por pessoas qualificadas nesse setor.

Observando esse cenário, também é crescente o investimento e implantação dessas tecnologias nos âmbitos escolares. Como exemplo, a Secretaria de Educação do Estado de São Paulo investirá em tecnologia nas escolas, a partir de 2013, cerca de R\$ 5,5 bilhões nos próximos 10 anos (NOTÍCIAS TERRA, 2012). Esse investimento tem fomentado discussões sobre novas práticas e métodos no processo de ensino e aprendizagem. Com essa disseminação dentro dos contextos escolares se provocou reflexões acerca das inovações pedagógicas que deveriam acompanhar esses avanços tecnológicos a fim de atingir o uso eficaz que se dê além do seu simples uso.

De acordo com Souza (2001), o processo de inserção dos recursos computacionais no contexto educacional ocorrerá sem maiores problemas quando houver uma quebra de paradigmas secular e for iniciada a busca pela construção de práticas que levem em consideração as tecnologias e suas possíveis repercussões para os currículos escolares.

Os alunos da atualidade estão envolvidos em ambientes colaborativos e cooperativos. Dessa maneira, cabe a escola reformular certas práticas para atingir esse novo perfil de aluno. Segundo Sampaio e Leite (2004), jovens têm mais facilidade de lidar com a linguagem dos meios digitais do que a linguagem escrita. Eles se identificam com os meios eletrônicos por carregarem características semelhantes. Dentre elas, a constante presença de informações visuais e o rápido processamento de múltiplos recursos simultâneos.

A tecnologia da informação tem influenciado crianças, jovens e adultos a buscarem todo tipo de informação, principalmente pelo fácil acesso à internet por meio de computadores, celulares, entre outros dispositivos móveis. No entanto, mesmo com todo esse potencial, observa-se que os jogos digitais educacionais ainda são pouco empregados em sala de aula. Balasubramanian e Wilson (2006) citam que muitos professores têm dificuldade em encontrar e utilizar bons jogos que auxiliam o processo de ensino e aprendizagem.

Para muitos professores, os Jogos são vistos como uma atividade inútil e sem finalidades educativas por apresentar um caráter "não sério". Contudo, ao jogarem, os alunos demonstram seriedade, concentração e como qualquer atividade lúdica, o jogo também é acompanhado de risos, de alegria e divertimento (KISHIMOTO, 2003)

De acordo com Sá, Teixeira e Fernandes (2007), a utilização de jogos nas atividades de ensino possibilita oferecer ao aprendiz momentos lúdicos e interativos como etapas do processo de aprendizagem. Os jogos têm a capacidade de auxiliar o professor, desde que os mesmos sejam desenvolvidos e trabalhados de forma crítica, possibilitando a aprendizagem significativa do aluno (GROS, 2003).

Nesse sentido, Alves (2005) ressalta que os jogos educacionais eletrônicos estimulam a reorganização de funções cognitivas como a criatividade, atenção, imaginação, coordenação motora e memória. Além disso, eles contribuem para determinar o modo de percepção e aprendizado pelo qual o sujeito conhece o objeto. Os professores precisam estar comprometidos com as possibilidades geradas pela interação dos jogos eletrônicos, os quais são poucos explorados pelas escolas e tendem ainda a reproduzir uma lógica linear e resistente às tecnologias dessa natureza. 
Nesse contexto, este artigo apresenta o relato de experiência de um projeto de extensão da Universidade de Pernambuco com o título: Aplicação e Desenvolvimento de Jogos Eletrônicos Educacionais. Os objetivos principais desse projeto envolve promover aos alunos e professores do ensino médio um melhor aproveitamento dos conteúdos abordados em sala de aula, introduzir conhecimentos básicos de lógica de programação, fomentar o trabalho em equipe e divulgar os benefícios que a Licenciatura em Computação pode oferecer a sociedade.

Como campo de trabalho, foi escolhida a Escola de Referência em Ensino Médio Deolinda Amaral localizada na cidade de Lajedo (PE), a $197 \mathrm{~km}$ da capital Recife. Pois os graduandos em Licenciatura em Computação participantes do Projeto estudaram nessa escola, perceberam oportunidades de melhoria no processo de ensino e aprendizagem naquele local e se sentiam na obrigação de devolver, para a escola, o conhecimento que estão adquirindo na graduação.

O presente artigo está estruturado da seguinte forma: a Seção 2 apresenta brevemente conceitos referentes aos Jogos Eletrônicos Educacionais e alguns trabalhos relacionados; a Seção 3 descreve os resultados do projeto; e a seção 4 apresenta as considerações finais e os trabalhos futuros.

\section{Jogos Eletrônicos Educacionais}

O jogo digital é uma das formas através das quais a tecnologia tem chegado à sala de aula. Diferentemente de muitas outras formas, o jogo digital é, por si só, motivador (Munguba et. al., 2003). Há diversos autores que definem o conceito de Jogos. Mas dentre eles, a definição que mais se enquadra com o presente artigo é esta "Os jogos digitais podem ser definidos como ambientes atraentes e interativos que capturam a atenção do jogador ao oferecer desafios que exigem níveis crescentes de destreza e habilidades" (BALASUBRAMANIAN E WILSON, 2006).

No momento em que o jogo é inserido no contexto educacional, ele recebe uma nova denominação, passando a ser chamado de jogos educacional, de acordo com (Lima et al., 2009). Kishimoto (2003) afirma que no campo educacional, há uma busca por conciliar a liberdade dos jogos com a orientação própria dos processos educativos.

Para que os jogos possam ser caracterizados como educacionais, eles "devem possuir objetivos pedagógicos e sua utilização deve estar inserida em um contexto e em uma situação de ensino baseados em uma metodologia que oriente o processo, através da interação, da motivação e da descoberta, facilitando a aprendizagem de um conteúdo" (Prieto et al., 2005, p. 10).

De acordo com Savi e Ubricht (2008), a utilização desses jogos traz consigo diversos benefícios ao processo de ensino aprendizagem, dentre eles:

- Efeito motivador, os jogos educacionais demonstram ter alta capacidade para divertir e entreter as pessoas ao mesmo tempo em que incentivam o aprendizado;

- Facilitador do aprendizado, os jogos têm a capacidade de facilitar o aprendizado em vários campos de conhecimento;

- Desenvolvimento de habilidades cognitivas, os jogos promovem o desenvolvimento intelectual, uma vez que para vencer os desafios o jogador 
precisa elaborar estratégias e entender como os diferentes elementos do jogo se relacionam.

- Aprendizado por descoberta, os jogos desenvolvem a capacidade de explorar, experimentar e colaborar.

- Experiência de novas identidades, os jogos oferecem aos estudantes oportunidades de novas experiências de imersão em outros mundos e a vivenciar diferentes identidades;

- Socialização, os jogos podem servir como agentes de socialização à medida que aproximam os alunos jogadores, competitivamente ou cooperativamente;

- Coordenação motora, diversos tipos de jogos digitais promovem o desenvolvimento da coordenação motora e de habilidades espaciais;

- Comportamento expert, jovens que jogam vídeo games se tornam experts no que o jogo propõe. Isso indica que jogos com desafios educacionais podem ter o potencial de tornar seus jogadores experts nos temas abordados.

Na literatura podem ser encontrados alguns trabalhos relacionados a este aqui apresentado. A pesquisa de Silva et al. (2011) descreve a aplicação de uma oficina de introdução a programação para os alunos do Ensino Médio. A oficina focou na linguagem de programação Python e utilizou jogos como fator motivacional para atrair os alunos e aumentar o seu interesse para o conteúdo apresentado e para a área de computação. Savi e Ubricht (2008) apresentou o potencial dos jogos digitais educacionais, baseado em estudos de especialistas, traz exemplos de jogos utilizados em diferentes níveis de ensino e aponta problemas que ainda precisam ser superados para facilitar o emprego dos jogos digitais educacionais. Por fim, Calisto, Barbosa e Silva (2010) apresentam o resumo de vários jogos educativos e realizam uma análise comparativa entre eles com a finalidade de identificar as principais tecnologias e métodos utilizados. Estes aspectos poderão ser utilizados para desenvolver um jogo para educação ambiental.

Diante das características apresentadas nos trabalhos relacionados, esta pesquisa tem como diferencial propiciar no mesmo momento a aplicação de jogos digitais como também permitir, aos alunos de uma escola de ensino médio, o desenvolvimento dos seus próprios jogos no ambiente Game Maker. Além disso, contou-se com a participação de professores da própria escola, os quais puderam acompanhar o desenvolvimento dos alunos e perceber os benefícios da aplicação e desenvolvimento de jogos digitais na educação.

\section{Resultados do Projeto}

A Escola de Referência em Ensino Médio Deolinda Amaral foi escolhida como um campo de trabalho porque os autores deste artigo estudaram nela durante todo o ensino médio. Com isso, foi possível identificar que não se utilizavam meios tecnológicos para auxiliar a aprendizagem das disciplinas básicas, tais como, português, matemática, física, etc. Como hoje os participantes deste projeto cursam Licenciatura em Computação, percebeuse uma oportunidade de voltar à escola para estimular os professores e alunos a utilizarem jogos eletrônicos educacionais como um meio de auxiliar o processo de ensino e aprendizagem

Antes de iniciar as atividades na escola, aplicou-se um questionário para 40 alunos com a intenção de investigar quantos deles utilizavam o laboratório de informática como 
um meio de aprendizagem. Como um principal resultado, observou-se que a maioria raramente utiliza com esse propósito. O Gráfico 1 demonstra justamente essa subutilização do laboratório na escola pesquisada.

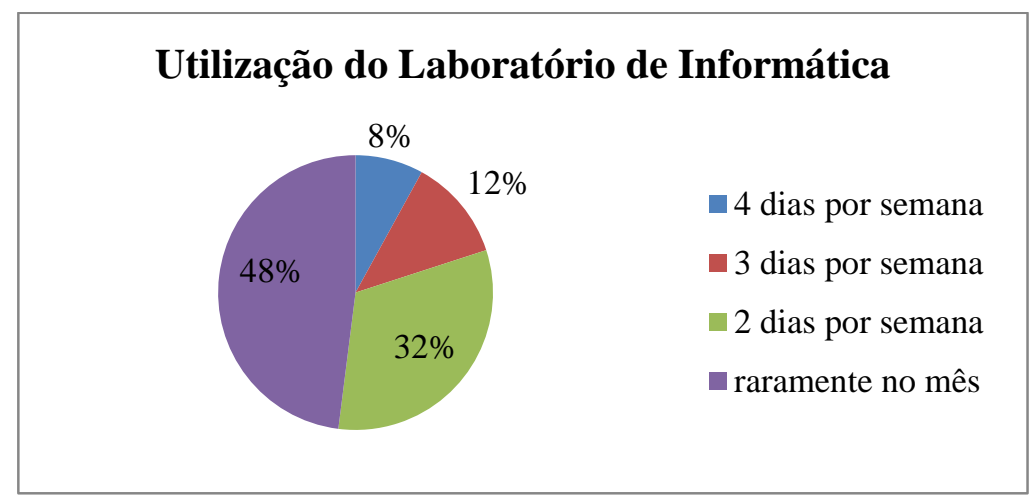

Gráfico 1. Utilização do laboratório de informática como um meio de aprendizagem.

Com a finalidade também de modificar esse cenário, o projeto realizado contemplou o uso consciente do laboratório através da aplicação e desenvolvimento de jogos educacionais. Este projeto contou com a orientação de um professor e três alunos de Licenciatura em Computação que atuaram como tutores no projeto de Aplicação e Desenvolvimento de Jogos Eletrônicos Educacionais. Como participantes da escola de Referência em ensino Médio Deolinda do Amaral, foram três professores, um de História, um de Geografia e outro de Física. Tiveram Vinte e cinco alunos inscritos, dos quais estavam distribuídos entre $2^{\circ}$ e $3^{\circ}$ ano. Essa quantidade foi limitada devido ao número de computadores disponíveis no laboratório. A sugestão por esses alunos partiu da própria escola porque os mesmos estavam se preparando para o vestibular.

Nesse projeto, foi exposta a importância do uso dos jogos educacionais como recurso de apoio à sala de aula. Houve também o alinhamento com os professores sobre os assuntos que eles abordam em sala de aula, para que o jogo utilizado ou desenvolvido no laboratório tenha relação com o assunto abordado e, consequentemente, o aluno possa obter maior assimilação do assunto.

O projeto foi dividido em três grandes fases. A primeira fase teve o objetivo de apresentar fundamentos teóricos sobre jogos eletrônicos educacionais. Na segunda fase foram apresentados alguns jogos já existentes que podem ser aplicados para auxiliar o ensino e aprendizagem. Por fim, a terceira fase propiciou aos alunos obterem a capacidade de construir seus próprios jogos e desafios através da plataforma Game Maker ${ }^{1}$. O curso foi executado no período de 3 meses, havendo uma aula por semana com duração de 3 horas, totalizando 36 horas de carga horária.

Após demonstrar os conceitos teóricos na primeira fase, as plataformas de jogos apresentadas aos alunos e professores que podem auxiliar o ensino foram Ludo Educativo $^{2}$, Sudoku do CMDMC ${ }^{3}$ e a Olimpíada de Jogos Digitais e Educação ${ }^{4}$ (OJE). O Ludo Educativo é um jogo no melhor estilo tabuleiro, porém com fins educativos. Nele, deve-se responder as perguntas de forma correta para vencer. Como o objetivo principal dos desenvolvedores é estimular o aprendizado escolar, as perguntas são pertinentes ao tema e ao nível dos participantes, além de haver premiação para os melhores jogadores.

O Sudoku do CMDMC utiliza os elementos químicos no lugar dos números. Com isso os estudantes, principalmente os de ensino médio, podem estudar de forma diferente 
uma parte importante da química, a tabela periódica e suas propriedades. Algumas das possibilidades são associar a sigla ao elemento, quais elementos pertencem a um mesmo grupo e etc.

E a Olimpíada de Jogos Digitais e Educação é um projeto inovador desenvolvido pela Secretaria de Educação de Pernambuco voltado para o aproveitamento educacional do potencial dos jogos digitais. Trata-se de uma Olimpíada anual na qual os alunos formam equipes, junto com os professores, para participar da competição que possui vários jogos que abordam conteúdos dados em sala de aula. Os enigmas são questões baseadas no padrão do ENEM. Com isso, os alunos têm uma oportunidade de utilizar positivamente a internet e o ambiente dos jogos eletrônicos, promovendo a integração e colaboração através do trabalho em equipe, a competitividade sadia e o incentivo à pesquisa de conteúdos relevantes.

A terceira fase do projeto se caracterizou pelo desenvolvimento dos jogos com a utilização da plataforma Game Maker. Antes da turma realmente começar a desenvolver seus próprios jogos, foram apresentadas conceitos pertinentes para os mesmos poderem desenvolver seus projetos, tais como:

- História do design de games. Nessa etapa foi discutido, quem é o Designer de Games, qual o seu papel no desenvolvimento do mesmo, a evolução dos Games, mudanças significativas até o cenário atual, linguagens de programação, ferramentas de autoria, jogos que marcaram história.

- Jogos eletrônicos e educação. Foi discutida a definição de Jogo, como também os "serious games" que são jogos com um propósito sério que pode ser utilizado de diversas formas, no projeto foi utilizado de forma educacional, foi abordado também suas Aplicações, Plataformas que podem ser utilizados, Modos de Jogar, Estilos, A importância do Jogo na Sociedade, Educação e Jogos na Resolução de Problemas.

- Game Maker 8.0. Foi apresentado a plataforma, que ela é caracterizada como um motor de jogo proprietário, desenvolvido pela YoYo Games. O mesmo tem suporte a uma linguagem de script, chamada GML. O Game Maker é escrito em Delphi, motivo pelo qual não tem versões para outros sistemas que não o Microsoft Windows.

- Elementos históricos e Tipologia dos games. Foram discutidos os elementos que perpassam na grande maioria dos jogos, todo jogo possui elementos históricos que servem para discussão de fatos, personagens entre outros conceitos históricos, foi apresentado também quais são os tipos de jogos existentes.

- Games e educação. Foi discutido o conceito de Games e Educação que foi caracterizado como atividades lúdicas que possuem objetivos pedagógicos especializados para o desenvolvimento do raciocínio e aprendizado. Também foi analisado se realmente pode se existir essa junção de games e educação e se existe um bom número de jogos desenvolvidos atualmente no Estado e fora dele.

- Narrativas interativas. Discutiu-se sobre a imersão que as narrativas podem trazer para o jogo e como construir narrativas interativas, foi abordado a Narração em

\footnotetext{
${ }^{1}$ Game Maker é um motor de jogo proprietário, desenvolvido pela YoYo Games, que pode criar jogos em 2D, 3D, jogos online e programas. Ver site: http://www.yoyogames.com/make
} 
Redação, Narração - Roteiro Cinematográfico, Monomito, Narração em Games baseado em Novak, Imersão x Efeito Cinemático e Formas de Manter o Usuário interessado no jogo.

- Personagens. Foi discutido a construção em questão de modelagem de personagens em 3D e 2D, os Tipos de personagens, Arquétipos de personagens, Protagonista x Antagonista, Tipos de Antagonista, Pontos de Vista, Movimento e Sinopse do personagem.

- Design de níveis. Discutiu-se as transições de níveis, como passar de nível sem que haja a quebra de imersão dos usuários, como também Estrutura dos níveis, Duração, Disponibilidade, Progressões, Espaço, Terrenos, Materiais, Realismo e Estilo.

- Regras do jogo. Foram discutidos que cada jogo tem um conjunto de regras básicas que devem existir que definem o que pode ser feito ou não como também para que o mesmo tenha início e fim, as regras também forçam de certa forma os usuários tomarem caminhos específicos para atingirem os objetivos e garantem que todos os jogadores tomam caminhos semelhantes.

- Plataformas e possibilidades. Foram apresentadas diversas plataformas como a UDK, Unity 3D e quais as possibilidades de desenvolvimentos nas mesmas.

- Documentação para o jogo, Projeto de Game. Finalização dos projetos com a documentação explicitando todas as etapas e os personagens objetos envolvidos no projeto.

Após as etapas apresentadas, os alunos formaram três equipes sendo duas compostas por oito e uma por nove alunos. Foi solicitado para que cada equipe elaborasse e apresentasse uma proposta de jogo para a turma juntamente com os três professores envolvidos. Posteriormente, aconteceu a discussão e aprovação das propostas visando à qualidade, os objetivos e viabilidade do desenvolvimento do jogo num determinado prazo. Ao final do curso, todos os jogos foram apresentados e cada equipe testou o jogo que foi desenvolvido por outro. Em seguida, houve uma votação para a escolha do melhor jogo. A seguir, são descritos os jogos desenvolvidos por cada equipe:

- A Equipe 1 desenvolveu, juntamente com o Professor de Geografia, um Jogo que consistia na apresentação das Paisagens Naturais da Cidade de Lajedo - PE e as Paisagens habitadas pelo homem.

- Equipe 2 desenvolveu, juntamente com o Professor de História, um jogo abordando os Povos Pré-colombianos tendo como base o jogo Age of Empires III.

- Equipe 3 desenvolveu juntamente com o Professor de Física um jogo abordando o assunto de Termodinâmica, onde foi desenvolvido um cenário em que os índios de uma aldeia tinham que proteger uma fogueira que estava acesa. Caso a fogueira fosse apagada pelos monstros que apareciam no cenário, o casamento que estava acontecendo na aldeia iria ter um fim trágico. Esse foi o jogo eleito pelos participantes como o melhor.

\footnotetext{
${ }^{2}$ Ver site http://www.ludoeducativo.com.br/site/

${ }^{3}$ Ver site http://www.cmdmc.com.br/sudoku/

${ }^{4}$ Ver site http://www7.educacao.pe.gov.br/
} 
Durante esse processo, foi percebido que alguns alunos demonstravam dificuldades em certas disciplinas. Para tentar solucionar esse problema, o auxílio dos professores foi fundamental, pois os tutores do curso auxiliavam as equipes de forma técnica na construção dos jogos, já os professores da escola auxiliavam pedagogicamente para que os jogos tivessem um objetivo bem definido dentro da área de conhecimento estabelecida.

Como resultado do projeto, tanto os alunos como os professores da escola perceberam que a utilização do laboratório de informática pode ser fundamental no desenvolvimento intelectual dos alunos. Constatou-se também que após a conclusão do curso, a escola obteve o aumento gradativo do uso do laboratório de informática. Dos três meses que foram analisados, notou-se que a frequência dos alunos do $2^{\circ}$ e $3^{\circ}$ ano cresceu $46 \%$. O Gráfico 2 demonstra justamente esse aumento no uso do laboratório da escola pesquisada.

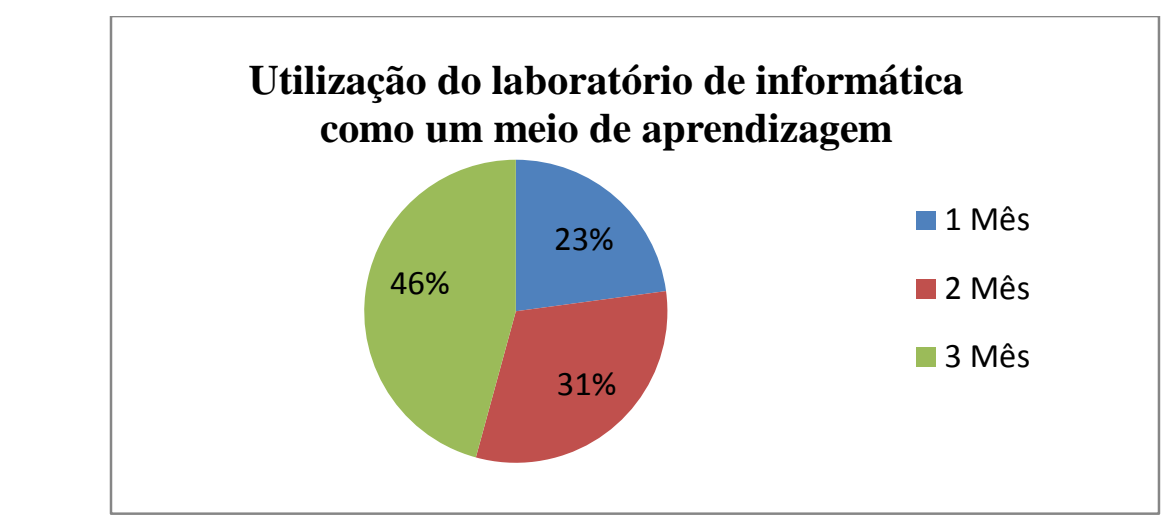

Gráfico 2. Utilização do laboratório de informática como um meio de aprendizagem

De acordo com os professores, este projeto foi de extrema importância para a escola. Pois propiciou aos alunos que pretendiam fazer vestibular uma forma lúdica de estudar, uma vez que os jogos aplicados traziam questões pertinentes de vestibulares de diversas Universidades, isso foi um dos aspectos mais motivadores do curso, pois os alunos além de estudarem estavam se divertindo.

Os professores envolvidos no curso demonstraram interesse na aplicação dos jogos educacionais, pois perceberam que com este auxílio, os alunos se divertem e se motivam enquanto aprendem. Segue um relato do professor de Física: "Pude perceber que a aplicação de jogos em minhas aulas faz com que os alunos interajam com mais facilidade e discutam os assuntos abordados em sala de aula"

\section{Considerações Finais}

De acordo com os resultados evidenciados neste artigo, fica claro que a aplicação de jogos educacionais é um importante meio de auxílio ao processo de ensino e aprendizagem. Esta pode ser mais uma forma de se utilizar os laboratórios das escolas públicas de maneira consciente e não apenas para entretenimento. Além desse modo de aprendizado fazer com que os alunos trabalhem em equipe para solucionar problemas, ele pode servir como fator motivacional para os alunos aprenderem matérias com altos índices de rejeição, como em matemática e física. 
Segundo Tarouco (2005), os jogos devem possuir regras, metas, interatividade, produzirem resultados e, indispensavelmente, serem divertidos. Todos esses elementos são essenciais para o sucesso de um jogo educacional num ambiente escolar. Para que isso se torne realidade, os jogos educacionais precisam ser desenvolvidos por equipes multidisciplinares para alcançar o total alinhamento entre diversão e o aprendizado pedagógico.

Diante do que foi vivenciado neste projeto, os autores deste trabalho sugerem que além da aplicação correta dos jogos educacionais relacionados com as disciplinas básicas, é preciso também estimular os próprios alunos a criar a ideia e desenvolver os jogos. Essa atividade estimulará diversas habilidades tais como, criatividade, cognição, trabalho em equipe, lógica matemática e pensamento computacional necessárias para resolver problemas reais.

Considera-se que o principal resultado deste projeto de extensão caracteriza-se pela percepção da mudança de realidade na Escola de Referência em Ensino Médio Deolinda Amaral. Pois antes do projeto, os alunos utilizavam o laboratório de informática apenas como forma de entretenimento e os professores não sabiam como utilizá-lo para auxiliar suas disciplinas. Após a sua finalização, tanto os professores como os alunos se sentiram motivados a utilizar uma parte da carga horária da disciplina no laboratório jogando e desenvolvendo novos jogos.

Dessa forma, os professores envolvidos observaram que o interesse dos alunos em relação as suas disciplinas aumentou e que os jogos utilizados no curso foram de grande importância para a preparação dos alunos para o vestibular, devido a forma lúdica de como os assuntos eram tratados. A partir da avaliação positiva desses resultados, sugerese que outras iniciativas sejam realizadas com base nas práticas apresentadas neste trabalho. Pretende-se num futuro próximo aplicar esse projeto em outras escolas da região, melhorar a forma de apresentação do curso ao incorporar mais jogos e transformar as práticas de desenvolvimento de jogos mais amplas e úteis para os alunos.

\section{Referências}

ALVES, L., (2005). Game Over: Jogos Eletrônicos e Violência. São Paulo: Futura.

Balasubramanian, N; Wilson, B. Games and Simulations. In: Society for Information Technology and Teacher Education International Conference, v.1. (2006).

Calisto, A; Barbosa, D; Silva, C. Uma Análise Comparativa entre Jogos Educativos Visando a Criação de um Jogo para Educação Ambiental. In: XXI Simpósio Brasileiro de Informática na Educação, João Pessoa, (2010).

Gros, Begoña. The impact of digital games in education. First Monday, v.8, n.7, jul. (2003). Disponivel em: http://www.firstmonday.org/issues/issue8_7/xyzgros/index.html. Acesso em: 22 out. (2007).

Kishimoto, Tizuko M. “O jogo e a educação infantil”. São Paulo, SP: Pioneira, 2003

Lima, Maria do Carmo Fernanda; Silva, Vanessa Valéria Soares; Silva, Maria Emília Lins (2009). "Jogos educativos no âmbito educacional: um estudo sobre o uso de jogos no projeto MAIS da Rede Municipal do Recife" 
Notícias Terra (2012). Governo de SP investirá cerca de 5 bi em tecnologia nas escolas. Disponível em: < http://noticias.terra.com.br/educacao/governo-de-spinvestira-cerca-de-5-bi-em-tecnologia-nas-

escolas,81c942ba7d2da310VgnCLD200000bbcceb0aRCRD.html>, Acessado em: $15 / 07 / 2013$.

Prieto, Lilian et al. Uso das Tecnologias Digitais em Atividades Didáticas nas Séries Iniciais. Renote: revista novas tecnologias na educação, Porto Alegre, v. 3, n. 1, p.111, maio (2005).

Revista INFO (2012). TI no Brasil movimentou US\$ 102,6 bi em 2011. Disponível em: $<$ http://info.abril.com.br/noticias/mercado/ti-no-brasil-movimentou-us-102-6-bi-em2011-14052012-35.shl>, Acessado em: 05/07/2013.

Sá, E.J.V; Teixeira, J.S.F; Fernandes, C.T (2007) Design de atividades de aprendizagem que usam Jogos como princípio para Cooperação. In: Anais do XVIII Simpósio Brasileiro de Informática na Educação (SBIE), São Paulo - SP, Brasil

Sampaio, Marisa N.; Leite, Lígia S. (2004) “Alfabetização tecnológica do professor”. $4^{\mathrm{a}}$ ed. Petrópolis: Vozes

Savi, R; Ubricht, Vania R. Jogos digitais educacionais: benefícios e desafios. Revista Novas Tecnologias na Educação. CINTED-UFRGS. Volume 6, Fascículo 2. (2008).

Silva, D. ; Costa, L.; Silva, M. A. A; Dantas, Ayla. Atraindo Alunos do Ensino Médio para a Computação: Uma Experiência Prática de Introdução a Programação utilizando Jogos e Python. In: XXII Simpósio Brasileiro de Informática na Educação, Aracajú, (2011).

Souza, Joselito L. de (2001) "Computadores e internet na escola: o que muda?" In Alves, L. R. G., Silva, J. B. "Educação e cibercultura”. Salvador: EDUFBA.

Tarouco, L. M. R. et al. (2005) O aluno como co-construtor e desenvolvedor de jogos educacionais. Revista Novas Tecnologias na Educação. V. 3. No. 2. Rio Grande do Sul, Novembro, (2005). 